\title{
Representaciones Sociales del endeudamiento del consumidor, diferencias por género, edad y grupos de renta
}

\author{
Verónica Peñaloza \\ Universidade Estadual do Ceará- UECE, Fortaleza, Brasil \\ Email: veronica.penaloza@uece.br \\ Felipe Gerhard Paula Sousa \\ Universidade Estadual do Ceará- UECE,Fortaleza, Brasil \\ Email: gerhard.sousa@uece.br \\ Helder Araujo de Carvalho \\ Instituto Federal do Maranhão- IFMA,Maranhão, Brasil \\ Email: helder.carvalho@ifma.edu.br \\ Marianela Denegri Coria \\ Universidade de la Frontera, Temuco, Chile \\ Email: marianela.denegri@ufrontera.cl
}

\begin{abstract}
Resumen: El endeudamiento es un problema social grave y creciente que aflige consumidores en todo el mundo. En ese contexto, el objetivo de este trabajo es conocer las representaciones sociales del endeudamiento y si esta representación difiere según las características socio-demográficas de la población. Para alcanzar los objetivos de la investigación, se realizó un estudio exploratorio-descriptivo con 831 individuos, de ambos sexos, diferentes edades y estratos sociales, en una ciudad del nordeste de Brasil. Los principales resultados mostraron que el fenómeno del endeudamiento va más allá de lo estrictamente financiero, una vez que fueran alzadas categorías semánticas involucrando factores cognoscitivos y afectivos, además de estructuras de las económico-financieras. Las complejas y heterogéneas representaciones encontradas abordan asuntos muy amplios que van desde causas comportamentales, compras y consumismo, pasando por el sistema financiero y crediticio, temas de coyuntura político-económica a situaciones que afectan a las personas, en términos de salud, y/o provocan sentimientos de vergüenza y/o malestar en general.
\end{abstract} les.

Palabras clave:Endeudamientopersonal; consumo; causas comportamentales; causas sociales; causas emociona-

\section{Social representations of consumer indebtedness, differences by gender, age and income groups}

\footnotetext{
Abstract: Indebtedness is a serious and growing social problem afflicting consumers around the world. In this context, the objective of this work is to know the social representations of indebtedness and whether this representation differs according to the socio-demographic characteristics of the population. To achieve the research objectives, an exploratory-descriptive study was carried out with 831 individuals, of both sexes, different ages and social strata, in a city in northeastern Brazil. The main results showed that the phenomenon of indebtedness goes beyond the strictly financial aspects, once semantic categories were raised, involving cognitive and affective factors, as well as economic-financial structures. The complex and heterogeneous representations found address very broad issues ranging from behavioral
} 
causes, purchases and consumerism, through the financial and credit system, issues of political-economic circumstances to situations that affect people, in terms of health, and / or cause feelings of shame and / or malaise in general.

Keywords: Personal indebtedness; consumption; behavioral causes; social causes; emotional causes.

\section{Representações sociais do endividamento do consumidor, diferenças por gênero, idade e grupos de renda}

Resumo: O endividamento é um problema social grave e crescente que aflige consumidores em todo o mundo. Nesse contexto, o objetivo deste trabalho é conhecer as representações sociais do endividamento e se essa representação difere de acordo com as características sociodemográficas da população. Para alcançar os objetivos da pesquisa, um estudo exploratório-descritivo, com 831 indivíduos, de ambos os sexos, diferentes idades e estratos sociais, foi realizado em uma cidade no Nordeste do Brasil. Os principais resultados mostraram que o fenômeno do endividamento vai além do estritamente financeiro, uma vez que categorias semânticas foram levantadas envolvendo fatores cognitivos e afetivos, bem como estruturas econômico-financeiras. As complexas e heterogêneas representações encontradas abordam questões muito gerais que variam desde causas comportamentais, compras e consumismo, passando pelo sistema financeiro e de crédito, temas de conjuntura político-econômica a situações que afetam às pessoas em termos de saúde; provocando-lhes sentimentos de vergonha e/ou desconforto em geral.

Palavras-chave: Endividamento pessoal; consumo; causas comportamentais; causas sociais; causas emocionais.

\section{Introducción}

El crédito que antiguamente era reservado para acontecimientos como la adquisición de una casa, situaciones de urgencia o imprevistos, y hasta oportunidades de inversión, hoy en día es empleado para el consumo corriente y muchas veces para pagar otras deudas contraídas con anterioridad.Pasamos de una sociedad que antes valorizaba un comportamiento austero, a una sociedad que procura la satisfacción inmediata de los deseos a través del consumo, siendo éste, el patrón de comportamiento actual y moderno (Furnham, 1984; Davies y Lea, 1995; Lea et al., 1993; Denegri, 2007).Como consecuencia, los niveles de endeudamiento de los consumidores han alcanzado un estado crítico en muchos países y parcelas cada vez mayores de la renta familiar están siendo destinadas a pagar las deudas (Dean et al., 2013).Según Lipovetsky (2007), la sociedad de "hiperconsumo" como él la denomina estaría organizada en nombre de la felicidad; la producción, la comunicación de masas, la educación, la diversión, etc. Todo estaría estructurado en función de esa felicidad. Así cuanto más la sociedad enriquece, mayor sería el consumo y la necesidad de consumir, fomentando e impulsando la mercantilización de las necesidades cuya satisfacción no está al alcance de todos y para lo que muchas veces se recurre al endeudamiento.

Según el Instituto Internacional de Finanças (IIF), las deudas de las personas físicas han crecido en Brasil en los últimos años a un ritmo mayor que el ingreso de las familias y que el crecimiento del Producto Interno Bruto (PIB). Para Gutmann y Plihon (2008), posterior al colapso del patrón oro de la década del 30, las reformas monetarias realizadas en el sistema financiero permitieron la creación de moneda mediante la expansión del crédito. El sistema bancario comenzó a financiar el rápido crecimiento económico a través de lo que vino a ser llamada la economía del endeudamiento.

La capacidad del sistema para proveer crédito barato permitió a los gobiernos aumentar sus déficits y a las empresas a adoptar tecnologías de producción en masa. Las políticas keynesianas de expansión generaron un continuo aumento de los niveles de endeudamiento para solventar los gastos. En ese esquema, el consumo de los hogares -el mayor componente del gasto en la economía- aumentó a 2/3 de la demanda agregada (década 50/60). La deuda de los hogares aumentó de 0,37 en 1947 a 0,80 a fines de los 60. Según estos autores, posterior a la época de endeudamiento, la época de "protagonismo de las finanzas”, el proceso de globalización y financiarización del capital eliminó las barreras coercitivas que impedían la libre circulación de capitales en todo el mundo, junto con el desarrollo de la tecnología de la información permitió el acceso la transferencia de excedentes de capital, permitiendo la concentración de capital financiero. 
Hoy en día, la relación crédito /PIB en el mundo es de aproximadamente 130\% y es incluso más alta en algunos países europeos. A pesar que para el caso de Brasil, esa relación no es tan alta en comparación a los niveles internacionales y está en el promedio de América Latina, de $47 \%$ a 50\%, las condiciones de endeudamiento no dejan ser preocupantes. El compromiso del ingreso mensual de las familias brasileñas con el servicio de la deuda (intereses y amortización) es aproximadamente el $43 \%$ su presupuesto, siendo que $24.6 \%$ de este total es para otros motivos que no son crédito hipotecario. La situación se agrava cuando observamos que $25 \%$ de las familias (con ingresos de hasta diez salarios mínimos) tienen cuentas vencidas y aproximadamente un 11,5\% no están en condiciones de pagar sus deudas (IPEA, 2019). La expansión del crédito que ocurrió de forma excepcionalmente rápida en la última década coincidió con el aumento en el endeudamiento de las clases de ingresos más modestas, mediante un aumento significativo en la participación de tarjetas de crédito. El endeudamiento via tarjetas de crédito hoy se presenta como el indicador de más elevada morosidad, lo que trae a discusión la vulnerabilidad del consumidor (Sbicca, Floriani, y Juk, 2014)

Desde el aspecto individual, el endeudamiento no es un problema que afecte solo a las clases más vulnerables o con limitaciones financieras, a pesar afectarlas más agudamente, el fenómeno en sí, va más allá de lo aspectos simplemente financieros, el endeudamiento es un fenómeno de múltiples causas (Stone y Maury, 2006; Denegri, 2007; Luzardi y Tufano, 2009; Dean et al, 2013) y por lo tanto debe ser preocupación de diversas áreas. Explicar el endeudamiento desde una visión individual del fenómeno, culpando únicamente al individuo por no saber gestionar sus recursos, sea por falta de educación financiera, o bien por excesos en su consumo, adicciones o compulsión a la compra, es una visión limitada del problema. Para Henning (2010) el endeudamiento es un problema social grave y creciente que no se refiere solamente al ámbito jurídico y que, para su comprensión y superación, sería necesaria la articulación de varias disciplinas como la psicología, servicio social, educación y economía, además del derecho y por qué no del marketing, como la otra cara del consumo. Sin embargo, según la autora, es sorprendente la poca atención los diferentes campos del conocimiento le dan al problema del endeudamiento. Este desinterés probablemente se debe a la visión limitada de que se trata de un problema individual y no social.

El endeudamiento, sus causas y consecuencias, no es un problema que deba preocupar solo a la ciencia económica, hasta por que esta se ha concentrado tanto en el uso de las estadísticas y modelos que parece haber perdido de vista su objetivo final. Como bien señala Costa(2015) un buen uso de la matemática y de la econometría, no bastan sino nos preocupamos de los problemas fundamentales de las personas: el empleo, la calidad de vida, la pobreza, la concentración de la riquezay la devastación ambiental. No son desconocidos los daños sociales y ambientales que la sociedad de hiperconsumo provoca, producto de un sistema basado en el individualismo, que transforma la naturaleza y las relaciones sociales en mercancías, y subyuga de todo a las fuerzas del mercado. Por lo tanto, desde la academia, se reconoce que es imprescindible proponer nuevos paradigmas que trasciendan las disciplinas, visiones interdisciplinares de problemas sociales estudiados hasta ahora de forma individual (Barkin, 2012).

Cuando nos concentramos en la visión individual del endeudamiento problemas fundamentales de contexto social dejan de ser abordados; la influencia de la cultura de consumo, el aumento de la oferta de crédito antes no disponible, el exceso de producción de bienes que deben ser vendidos y el hasta el papel que el marketing tiene en todo ese proceso, incitando muchas veces al continuo a endeudamiento. Es bajo este contexto que evidenciamos una laguna en el entendimiento del fenómeno de endeudamiento desde una perspectiva más ampliaen las ciencias socialesy para eso nos valemos del enfoque de las representaciones sociales que permite incluir aspectos de las ciencias sociales en general, sin una visión reduccionista. La investigación social desde la perspectiva de las representaciones sociales, a diferencia de otros enfoques analíticos de las ciencias sociales, implica en una forma bastante peculiar de delimitar el objeto de estudio, ya que su mirada se centra en el proceso de construcción de sentido que los sujetos llevan a cabo respecto de su vida en sociedad(Torres,O; Garces A, 2013).

Así, este trabajobuscaconocercuál es el significado del endeudamiento, a través de la representación social del concepto, según características socio demográficas de la población y saber si esa representación tiene similitudes o difiere según género y para grupos de diferentes edades y diferentes niveles de ingresos.Como se señala anteriormente, a pesar que el endeudamiento es un problema social serio, no es exclusivo de los grupos 
de menores ingresos, las consecuencias del endeudamiento pueden ser mucho más severas para estos grupos. Por esta razón, la investigación se desarrolla en Ceará región nordeste de Brasil, conocida por ser una de las regiones más pobres de Brasil. Según datos de la última PNAD (2015)(Pesquisa Nacional de Amostra de Domicilios) calculada por Instituto Brasileño de Geografía y Estadística (IBGE), organismo público de administración federal, 88,9\% de las familias residentes en domicilios particulares permanentes de la región nordeste, ganan hasta 2 salarios mínimos.

\section{Concepto de Endeudamiento y sus Causas}

La mayoría de los trabajos que se refieren a actitudes al endeudamiento tratan sobre sus causas sin abordar claramente lo que el constructo en si significa. Parece no existir una clara definición del significado teórico del concepto, llevando a confusiones en el entendimiento y dimensión del endeudamiento de los individuos. A modo de ejemplo, ¿el uso de la tarjeta de crédito, es una deuda contraída, o es un medio de pago? Contreras et al. (2006) definen endeudamiento como la existencia de una obligación que será obliterada después del pago, caracterizada por el consumo anticipado y donde basta contraer la deuda para encuadrarse como endeudado. Entretanto, Leaetal. (1993), Tokunaga (1993) y Livingstone y Lunt (1992), ya entienden el endeudamiento como producto de una acción involuntaria de acúmulo de deudas, donde no hay intención deliberada del hecho. El endeudamiento también es visto (Dwyer, Mccloud y Hodson, 2011; Disney y Gathergood, 2011; Ottaviani y Vandone, 2011) como un desvío de cognición que implica desequilibrio en la toma de decisiones, desvío que es intensificado por la impulsividad de las personas que utilizan el endeudamiento como medio que alcanzar sus deseos y objetivos en el corto plazo. Otros autores entretanto, abordan el endeudamiento no como el resultado de malas decisiones, sino como una consecuencia de la elección entre ahorrar o disfrutar de algo, siendo una acción consciente en la que se asume el riesgo, pasando a estar endeudado. (Bruski y Magalhães, 2006; Harrison, Agnew y Serido, 2015).Si delimitar lo que se entiende por endeudamiento, ya es algo impreciso donde no existe pleno consenso, los factores que son señalados como causas de este fenómeno, son de muy amplio espectro; van desde causas financieras, las más comúnmente mencionadas, a factores de comportamiento individual, no dejando de lado las causas de origen macro-social, relacionadas al sistema financiero y la coyuntura económica.

Históricamente han sido los factores financieros los señalados como los predictores más importantes de endeudamiento. Estudios que vinculan el endeudamiento a razones puramente financieras, señalan que la deuda es producto de restricciones de orden monetaria, tales como bajos salarios e ingresos, altas tasas de interés y problemas de acceso al crédito, etc. (Joo y Grable, 2004; Beal yy Delpachitra, 2003; Mansfield y Pinto, 2008; Dwyer, Mccloud y Hodson, 2011; Awanis y Cui, 2013).El bajo nivel de educacional de las personas, el bajo nivel de educación financiera y así como la mala planificación y la gestión del presupuesto, también han sido nombrados como atributos responsables del aumento de endeudamiento mundial(Denegri; 2007; Dwyer, Mccloud y Hodson, 2011). Para los defensores de este enfoque, cuanto mayor es el nivel educacional y la alfabetización financiera de la persona, mayor es la posibilidad de tener las respuestas adecuadas a las cuestiones económicas. La educación en las finanzas del hogar así como también, la planificación, ayudarían en la gestión de los gastos de los hogares y contribuirían positivamente en relación al endeudamiento (Denegri, 2007; Dwyer, Mccloud y Hodson, 2011).

Con el pasar del tiempo, los estudios que relacionan el endeudamiento a factores de comportamiento vienen adquiriendo importancia.. Factores tales como la autoestima, locus de control, el comportamiento con respecto al riesgo, hábitos de uso de dinero en efectivo, estilo de vida, valores personales, entre otros, comienzan a ganar protagonismo en la predicción de endeudamiento (Livingstone y Lunt, 1992; Kidwell y Turrisi, 2003). Bajo esta perspectiva, el fenómeno del endeudamiento es algo más que un problema de comportamiento simplemente financiero. Factores psicológicos tienen una acción diferenciada en la actitud hacia el consumo y el endeudamiento e influencian este en diferentes grados.El endeudamiento ocurre a partir de causas intrínsecas a los individuos, son las creencias, los valores y las características psicológicas personales que guían a los consumidores a comprar y a endeudarse (Kidwell y Turrisi, 2003).

Otro aspecto que no podemos dejar de lado cuando hablamos de endeudamiento, son los problemas de salud física y mental que genera el estar endeudado. El fenómeno del endeudamiento ha sido largamente deba- 
tido, siendo identificado como un factor importante en la aparición de problemas mentales, como la ansiedad, el estrés, la preocupación y la ira y hasta depresión queno pocas veces puede culminar en intento de suicidio (Brown, Taylor y Price, 2005; Jessop et al., 2005; Cooper et al., 2008)

En vista de la pluralidad de aspectos causantes del fenómeno del endeudamiento, así como también las consecuencias negativas que de él se derivan, surge la necesidad de conocer cuál es la concepción que las personas en general, o bien un grupo social en particular, tienen sobre el endeudamiento. Interesa particularmente conocer cuál es la representación social del endeudamiento en grupos de diferentes contextos socioeconómicos.

\section{Metodología}

Se llevó a cabo un estudio exploratorio-descriptivo de naturaleza cualitativa con 831 individuos, de ambos sexos y diferentes edades y estratos sociales, los que fueron accesados mediante una muestra de carácter incidental (Aaker, Kumar y Day, 1995). La investigación ocurrió en ambientes públicos diferentes para poder abarcar el mayor número de personas, de diferentes estratos socioeconómicos y edades. Las entrevistas se realizaron en terminales de buses de la cuidad, facultades y lugares de recreación; plazas públicas y el sector de la costanera. Se privilegiaron los ambientes públicos y recreativos, evitando instituciones bancarias/financieras y lugares de compra, para evitar sesgos en la investigación,dada la connotación negativa del término endeudamiento. El levantamiento de las informaciones se dio durante el periodo de mediados de 2015 a inicios de 2017, en semanas normales sin festividades o feriados prolongados.Para la obtención de los propósitos del estudio en la recolección de los datos fue utilizada la técnica de evocación libre de palabras (Vergara, 2008). Esta es una técnica asociativa ampliamente utilizada en la investigación de las representaciones sociales. La técnica se caracteriza como un abordaje del sentido común, elevándolo a la categoría de conocimiento legítimo y, sobretodo, situándolo mientras tela de significados, capaz de portar consigo material conceptual suficiente para captar determinado recorte de la realidad social (Moscovici, 1984). De esa forma, la idea central de la evocación de palabras desvendar la asociación de ideas subyacentes a determinado grupo de individuos hasta llegar a la representación social del fenómeno-La finalidad al estudiar las representaciones sociales es la de conocer la forma en que un determinado grupo humano construye su conjunto de saberes (Moscovici, 1984). Tales conocimientos, una vez compartidos son responsables de constituir la conciencia del grupo social, expresan más que simples opiniones, revelando su identidad (Oliveira, Werba, 2008). La teoría de las representaciones sociales tiene como ventajas la capacidad para describir un fenómeno y también la eficiencia para poner en evidencia una realidad social subyacente. La teoría de las representaciones sociales (RS) por permitir comprender el proceso de la organización las representaciones que los propios profesores construyeron, en medio de un contexto tan complejo de múltiples facetas a cerca de enseñar, una vez que Esta construcción sociocognitiva compartida grupalmente influye en las actitudes, en los comportamientos, en el desempeño de la profesión y en los conocimientos que son elaborados y socializados en el cotidiano escolar. En resumen, una RS funciona como un sistema de interpretación de la realidad y determina los comportamientos y las prácticas de los sujetos.

Las representaciones sociales buscan tanto la coherencia y la homogeneidad, así como también la diversidad y la incoherencia en lo común y compartido. La estructura de la representación social es, fruto de la suma del análisis de asociación de ideas de varios individuos a una o más preguntas (Spink, 1994). Geertz (1983) ratifica tal perspectiva al sostener que, dada la imposibilidad de buscar lo estable y lo consensual en el análisis del sentido común, no hay como trazar estructuras lógicas subyacentes uniformes a todos los sujetos sociales Simplemente porque no existen. Porque sus contenidos son esencialmente heterogéneos, no se encuentra tan sólo con la lógica de la coherencia en el estudio de las representaciones sociales, sino también con la contradicción.Así la teoría de las Representaciones Sociales será usada para analizar los conocimientos, opiniones, sentimientos, ideas y hasta e imágenes que las personas tienen y expresan a través de la evocación de palabras sobre el concepto de endeudamiento.

En la Teoría de las Representaciones Sociales se distinguen por lo menos tres enfoques: el primero, representado por Denise Jodelet ; es una continuidad de la obra original, tiene un sesgo más antropológico. El segundo, a través de Willem Doise, se centra en las condiciones de producción y circulación de las representa- 
ciones sociales y el tercero, representado por Jean Claude Abric que pone énfasis en la dimensión cognitivaestructural y es conocido como la Teoría del Núcleo Central. La corriente estructuralista iniciada por Abric es una de las más difundidas en Brasil y piensa las representaciones sociales en dos grandes sistemas, el sistema central y los sistemas periféricos.

Se realizaron entrevistas estructuradas de corta duración (en promedio 5 a 7 minutos) en las cuales se preguntaba a los entrevistados las cinco primeras palabras que les venían a la mente cuando se les mencionaba la palabra inductora "endeudamiento". Los entrevistados también respondieron preguntas de carácter sociodemográfico, con ítems referentes a la edad, ingresos familiares, número de personas en la familia y escolaridad.

Las palabras y expresiones obtenidas fueron clasificadas con base en un sentido próximo. Después de la categorización, fueron retirados los términos que no presentaban relación semántica con ninguno de los grupos creados. Posteriormente se ponderaban las frecuencias absoluta y relativa de las categorías, por medio del cálculo de la orden media de evocación (OME); observándose el orden en la cual la palabra o expresión fue citada por el entrevistado. Inicialmente los datos fueron analizados de acuerdo con el enfoque estructural de las representaciones sociales (Abric, 2000), mediante un análisis prototípico, que es una técnica que busca identificar la estructura representacional a partir de los criterios de y orden de evocación de las palabras basada en los trabajos de Verges (1992).Finalmente, se elabora un gráfico cartesiano con las categorías semánticas encontradas, de modo de poder identificar el núcleo central de la representación, los términos más consensuales, vale decir las palabras nombradas con mayor frecuencia y evocadas antes. Para verel grado de relación entre las categorías de cada variable, con los datos demográficos de edad e ingresos se utilizael "Método de Análisis de Correspondencia (ANACOR) que se deriva de la conocida técnica factorial de componentes principales.El Análisis de Correspondencia Múltiple es una técnica de análisis de datos que usa datos categóricos nominales que ayudan a localizar y representar estructuras subyacentes en un conjunto de datos. Esto se logra mediante la representación los datos como puntos en un espacio euclidiano.

\section{Resultados y Discusión}

Con relación a la caracterización de la muestra, se trata de376 mujeres (45,2\%) y 455 hombres (54,8\%), con una renta promedio familiar de 4,39 salarios mínimos y una edad promedio de 39 años. El 32,9\% tiene hasta 24 años, el 40,7\% tiene de 25 hasta 59 años y 26,4\% tiene60 años o más.

Fueron evocadas un total de 3.073 palabras, que se redujeron a 2.532 palabras o expresiones diferentes, las que posteriormente se juntaron con sus sinónimas y se clasificaron en 9 grupos en función sus significados similares. Fueron excluidas 538 palabras que fueron nombradas una única vez y no consiguieron ser incluidas en ninguna categoría.

\section{Representación social general}

Posterior a la clasificación de los grupos, el cálculo de las frecuencias y la orden de evocación media, se procedió a la construcción de los cuadrantes.En el primer cuadrante se agrupan las evocaciones más frecuentes, y más importantes, es decir, las categorías de mayor consenso y las que probablemente constituyen el núcleo central de la representación. En el segundo y cuarto cuadrantes se ubican las categorías de importancia fundamental, sin embargo, de menos consenso que las del primer cuadrante y que representan la periferia de la representación. En el tercer cuadrante están las categorías menos evocadas por los encuestados y, por tanto, menos representativas del fenómeno.

En la figura 1, se observa la representación social del endeudamiento para todas las personas que componen el corpus de investigación. 


\section{Figura 1.}

\section{Representación Social del Endeudamiento General}

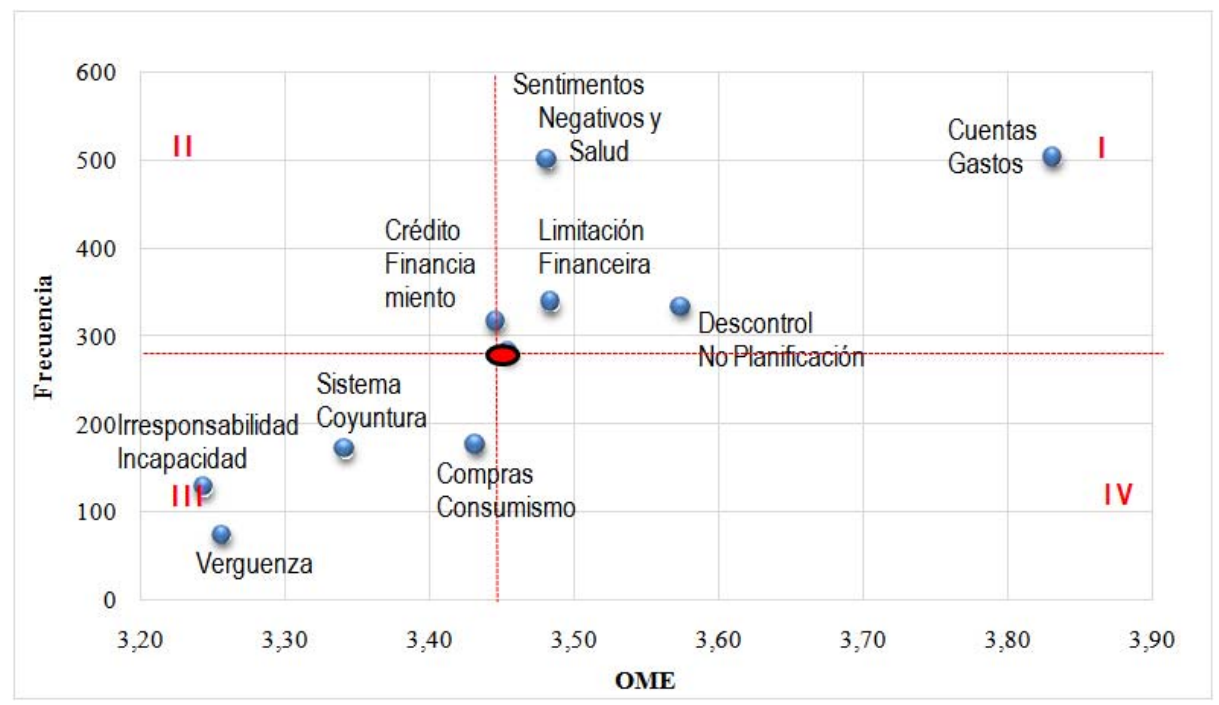

Fuente: Elaboración propia.

El Primer Cuadrante, que representa el núcleo central de la representación social, es donde se encuentran las palabras más frecuentes y prontamente evocadas, que son los términos más consensuales. Este cuadrante está compuesto por los conjuntos definidores “Cuentas/Gastos”, “Limitación Financiera”, “Descontrol/No Planificación” y “Sentimientos Negativos y Cuestiones de Salud”. El conjunto semántico “Cuentas/Gastos” agrupa palabras que remiten a la propia definición de endeudamiento e indica una característica propia de la deuda (e.g. deudas, cuentas, gastos, pagos, obligación), ya que endeudarse implica necesariamente adquirir y acumular, aunque involuntariamente, deudas, facturas, gastos (Livingstone y Lunt, 1992; Lea et al., 1993; Tokunaga, 1993). El conjunto de palabras “Limitación Financiera”, por otro lado, agrupa expresiones como falta de dinero, aprietos, restricciones y también limitación financiera, que indican claramente restricción de recursos. Este grupo pone de relieve las limitaciones de renta de la población (Joo y Grable, 2004).

Con un sentido semántico diferente, el conjunto definidor “Descontrol/No Planificación”, está conformado por palabras como mala administración, falta de control, desorganización financiera y la falta de planificación en si misma, no indica problemas con limitación financiera, sino que dificultades en administrar los ingresos. La importancia alcanzada por ese grupo definidor revela que aspectos de orden personal también están íntimamente relacionados con el fenómeno del endeudamiento (Bruski y Magalhães, 2006, Trevisan, 2012, Harrison, Agnew y Serido, 2015), aunque tales características sean compartidas y transmitidas socialmente (Davies y Lea, 1995; Denegri, 2007; Lipovetsky, 2007). También pone de relieve la falta de costumbre de planificar el presupuesto familiar, y la falta de conocimiento financiero (Denegri, 2007).

Por último, en medio de grupos que aportan sentidos relacionados, principalmente, a la racionalidad del fenómeno, la categoría “Sentimientos Negativos y Salud” evidencia un fuerte significado de orden emocional en la representación. Una vez que el grupo se constituye, esencialmente, por expresiones como depresión, angustia, miedo, ansiedad, sentimiento de culpa, desesperación, dolor de cabeza, estrés, además de las palabras salud y enfermedad, este grupo indica claramente que el endeudamiento sería capaz de ocasionar reacciones emocionales perjudiciales a los individuos (Drentea y Lavrakas, 2000). Ya el grupo "Crédito/Financiamiento", está formado por palabras como crédito, tarjeta de crédito, financiamiento y bancos, representando factores de influencia extrínsecos en el endeudamiento y que se refieren específicamente al sistema crediticio y de financiamiento que posibilita que las personas se endeuden. 
En este caso la representación está bien extrema, los grupos se concentran en el núcleo central, y luego en el cuadrante III, que corresponde a las palabras menos citadas y de menor prioridad en la evocación, corresponden a términos menos consensuales en la evocación.

Las otras categorías son menos relevantes para un análisis, las que se encuentran en la periferia de la representación y que conllevan significados menos consensuales delendeudamiento, corresponden a los grupos; "Compras / Consumismo”, "Sistema / Coyuntura Político-Económica” grupo donde agrupada toda y cualquier palabra que hiciera referencia a situaciones políticas o de índoles económica, palabras que van desde términos económicos como por ejemplo inflación a hasta los nombres de los presidentes o políticos del país. El otro grupo que también se ubica en esta periferia es el que fue denominado como "Irresponsabilidad e Incapacidad " donde fueron agrupadas todas las palabras, además delas específicas del título del grupo, las que representan incapacidad y falta de voluntad de la persona de cumplir, y por último el grupo que denominamos de "Verguenza" englobando, vergüenza, deshonestidade, nombre "sucio" o en los sistemas de cobranza, deshonra y otros similares.

\section{Representación social según perfil socio demográfico}

\section{Por Género}

En primer lugar,se analizó la representación social del endeudamiento en función del género. Como se observa en la figura 2, la palabra endeudamiento remite a asuntos bien diferentes para los hombres que para las mujeres. Para los primeros, de forma bien más concreta, el endeudamiento representa, créditos, financiamientos, cuentas, gastos, limitaciones financieras y materias de tipo político, económico y un poco más distante, puede ser asociado con irresponsabilidades e incapacidades. Ya para las mujeres, endeudamiento remite a asuntos de tipo comportamental, compras y consumismo, descontrol y falta de planificación y más lejanamente, vergüenza y sus afines.

Figura 2

Representaciones Sociales del Endeudamiento según Género

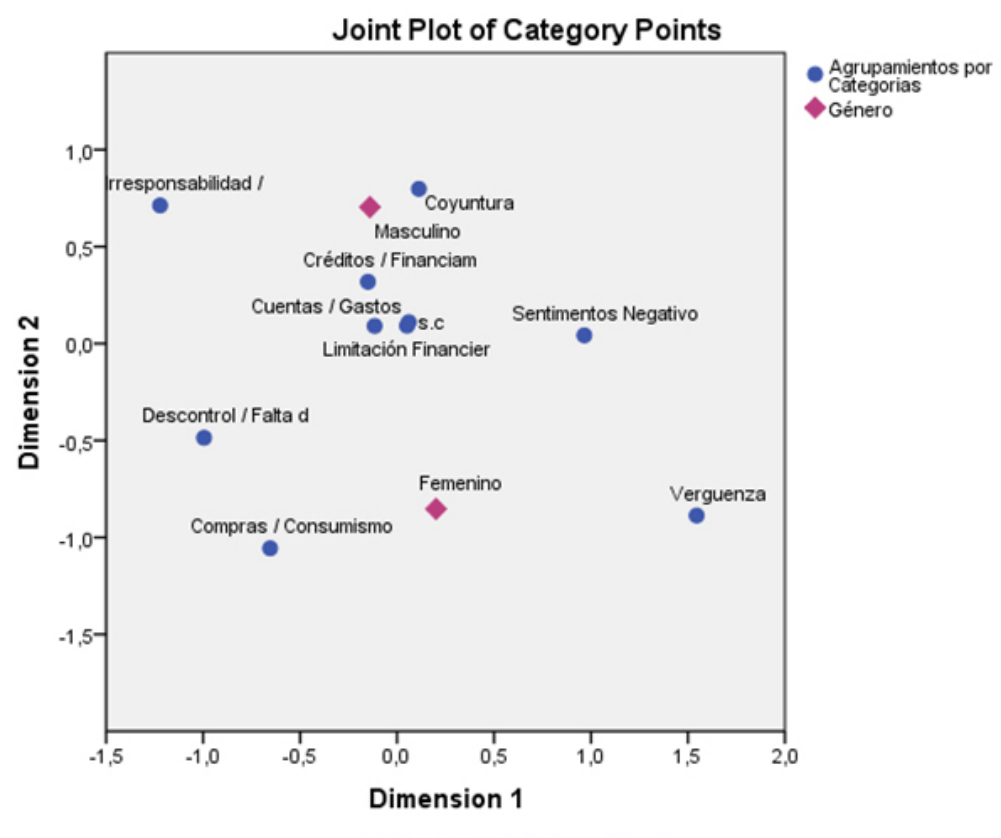

Variable Principal Normalization.

Fuente: Elaboración propia. 


\section{Por Edad}

Posteriormente se realizaron análisis de las representaciones de los entrevistados agrupándolos en grupos por edad, los individuos se dividieron en tres grupos: hasta 24 años $(n=273)$; entre 25 y 59 años $(n=338)$; y mayores de 60 años $(n=219)$. La división de los grupos fue realizada con el propósito de obtener representaciones con cierto grado de homogeneidad y coherencia. Fueron usados los límites cronológicos de la adolescencia de la Organización de las Naciones Unidas (ONU), criterio utilizado principalmente para fines estadísticos y políticos, que engloba a jóvenes adultos. El resultado puede observarse en la figura 3, a continuación.

Figura 3.

Representaciones Sociales del Endeudamiento Según Grupos de Edad

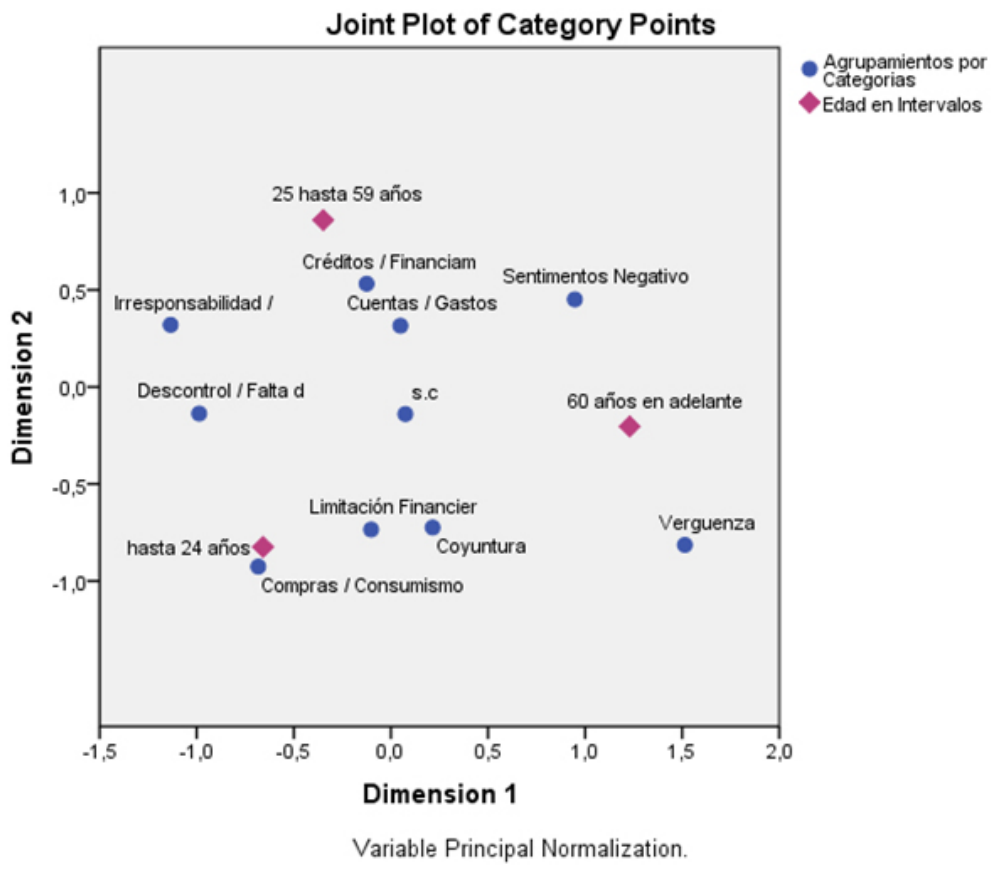

Fuente: Elaboración propia.

Por lo que se observa en la figura 3, la representación social del endeudamiento es diferente según la edad y también parecería estar asociada al ciclo de vida de las personas. Los jóvenes entienden el endeudamiento de forma diferente de cómo lo entienden las personas de la tercera edad y también difieren en su concepción del grupo de personas, entre 25 y 59 años. La representación del endeudamiento para los jóvenes está más ligada a las categorías "Compras/Consumismo", también a "Limitaciones Financieras” y un poca más lejana en su representación aparece la categoría "Coyuntura” que agrupa las nominacionesrelacionadas a cuestiones externas que tienen que ver con la política y la economía. Ya cuando aumentamos en edad, el grupo de los adultos, donde incluimos personas de 25 a 59 años, la representación de la deuda para este grupo está más asociada a la idea de "Créditos/Financiamentos” y "Cuentas/Gastos", lo que se vislumbra coherente con la etapa de vida que estas personas viven. Al observar la representación del grupo de individuos de tercera edad, la representación del endeudamiento se muestra bastante diferente de los grupos anteriores, en este caso los individuos construyen una imagen del endeudamiento basada en elementos de característica fundamentalmente emocional. Las principales categorías definitorias de ese grupo son las categorías agrupadorasde "Sentimientos Negativos y Salud" y lo que fue denominado de "Vergüenza"lo que indica que el endeudamiento es capaz de generar un efecto emocional negativo mayor sobre individuos mayores de 60 años, alertando para una grave consecuencia ocasionada en personas esencialmente más vulnerables. 


\section{Por Grupos de Ingreso}

Se realiza un nuevo análisis utilizando como base grupos de ingresos. Los grupos fueron divididos de la siguiente forma: clase $\mathrm{E}$ (hasta 2 salarios mínimos mensuales; $\mathrm{n}=316$ ); Clase $\mathrm{D}$ (entre 2 y 4 salarios, $\mathrm{n}=227$ ); Clase C (entre 4 y 10 salarios $n=209$ ); Clase AB (por encima de 10 salarios, $n=59$ ). Las agrupaciones se realizaron utilizando los mismos criterios del análisis anterior. La FIG. 4 presenta los principales resultados encontrados:

Figura 4.

Representaciones Sociales del Endeudamiento según Grupos de Ingresos

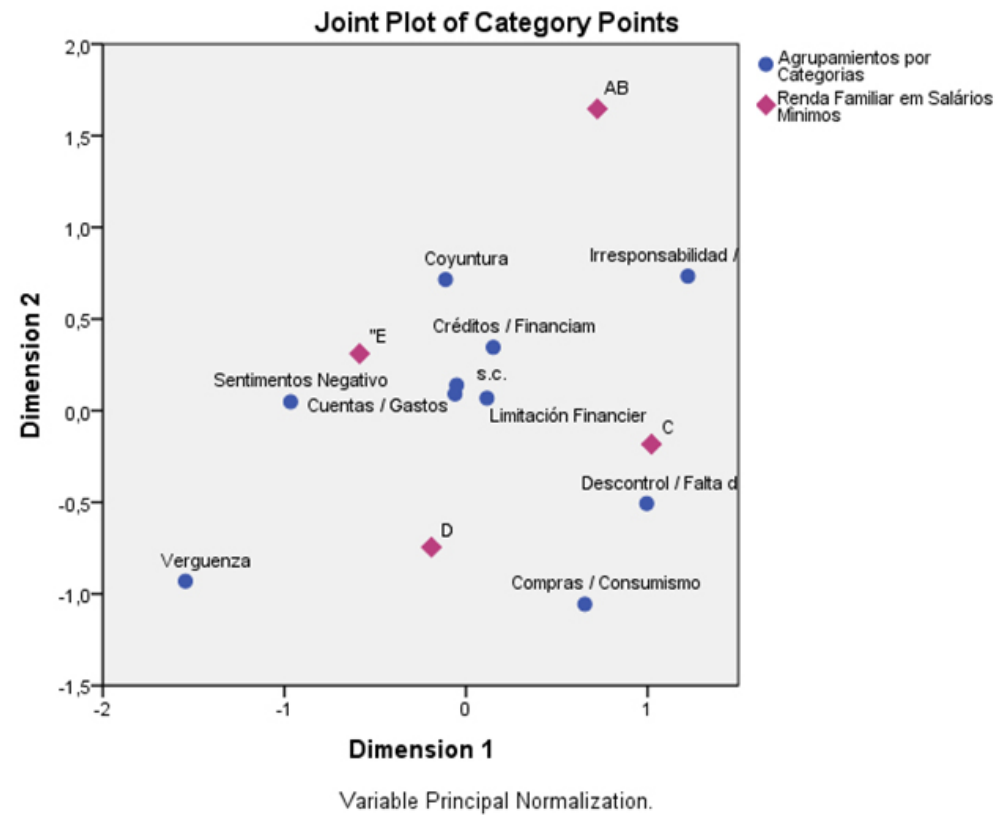

Fuente: Elaboración propia.

Los datos muestran que el grupo de las clases sociales más acomodadas poseen como categorías semánticas más representativas los conjuntos Irresponsabilidad e Incapacidad, así comocategoría Coyuntura, referida a asuntos políticos/económicos.Estas prestan poder semántico para describir el fenómeno del endeudamiento paras a las clases A y B, pero sólo marginalmente, de forma más distanciada. La Clase $\mathrm{C}$ ve el endeudamiento fundamentalmente como Descontrol y Falta de planificación y de forma más marginal como limitaciones financieras y compras/consumismo. Para estos sectores la representación del endeudamiento se presenta relacionada a factores intrínsecos y de responsabilidad del propio individuo. Para la Clase D la representación no es muy clara, de forma más periférica asocia endeudamiento con Compras y Consumismo y de forma bien distanciada con Vergüenza. Por último, el grupo constituido por los individuos de menor renta trae aspectos aún más diferenciados a la representación del endeudamiento. "Cuentas / Gastos”, Limitaciones Financieras y Créditos e Financiamientos, definen claramente la representación de endeudamiento para este grupo. Indicando la importancia del fenómeno en el cotidiano de esos individuos, en constante lidia con cuestiones de orden financiero. Las decisiones económicas impregnan el día a día de individuos de menor poder adquisitivo y asumen una importancia mucho mayor de lo que tendrían a las personas de las demás clases. Cada decisión debe ser bien calculada para no comprometer el presupuesto familiar, lo que origina a menudo el parcelamiento o la financiación de las compras. El endeudamiento surge como una combinación de estos factores, ocasionando también, la aparición de una reacción emocional que impacta con mayor vigor sobre grupos esencialmente más vulnerables. La categoría “Sentimientos Negativos" representa el endeudamiento por medio de atributos que escapan a 
una racionalidad cuantitativa y causal, ratificando la complejidad del fenómeno y la emergencia de su enfrentamiento por el sesgo del propio individuo.

\section{Conclusiones}

Existe consenso en que el endeudamiento tiene una connotación negativa, a veces moralizadora, que puede llevar a los endeudados a cargar sentimientos de culpa y estigma, provocando trastornos que van desde simples preocupaciones hasta ansiedad, angustia o depresiones más serias. A pesar del relativo consenso cuanto a la noción negativa del fenómeno, su entendimiento, así como sus causas están lejos de ser consensuales. El endeudamiento se destaca por dos aspectos dificultosos: la complejidad de la temática y la delimitación de las fronteras teóricas. Por su diversidad conceptual, permea diversas áreas de las ciencias sociales, la visión de una única área es insuficiente para explicar el endeudamiento, siendo necesaria una interrelación de áreas teóricas que tratan del tema. Por eso optamos por intentar entender el endeudamiento desde una perspectiva psicosocial bajo el prisma de las representaciones sociales.

El fenómeno del endeudamiento va más allá de lo estrictamente financiero, y no se trata sólo de restricciones de recursos, de hecho, los resultados de este estudio muestran que la representación social del endeudamiento aborda asuntos muy amplios que van desde causas comportamentales, compras y consumismo, pasando por el sistema financiero y crediticio, temas de coyuntura político económica y situaciones que afectan a las personas, en términos de salud, y/o provocan sentimientos de vergüenza y/o malestar en general. Las categorías contribuyen para la formación de un conjunto complejo y repleto sentidos, involucrando factores cognoscitivos y económicos afectivos, dificultades y problemas enfrentados para la población, lógicas y conocimientos colectivos, estructuras y sistemas sociales y privados.

Los resultados mostraron también que el entendimiento del endeudamiento difiere según género, edad y grupos de ingresos. Para los hombres la representación del endeudamiento está asociadaa asuntos financieros bien concretos, ya las mujeres entienden el endeudamiento asociado a causas comportamentales, no financieras y las consecuencias las afectan emocionalmente.

La representación de endeudamiento también difiere por edad pudiendo ser asociado al ciclo de vida de los individuos. Para el grupo más joven concentrase en signos de transgresión financiera y limitación económica-en parte fruto de un ethos pro-consumismo y de satisfacción material inmediata- el grupo de grupo de edad superior representa el fenómeno tanto por medio de factores extrínsecos que componen el sistema socioeconómico actual y por medio de factores intrínsecos relacionados a las facultades del propio individuo.Si imaginamos que está etapa está relacionada, por lo general, con la fase de consolidación de la familia y empleos más estables, en esa fase de vida aumentan los préstamos y financiamientos para casa y otros bienes durables, así como las cuentas asociadas también al crecimiento y afianzamiento de la familia; pagos de escuelas, arriendos, seguros etc.

En la región nordeste brasileña, principalmente fuera de los grandes centros, por sus condiciones socio económicas, no es poco común, que los adultos mayores vivan en familias ampliadas compuestas por personas de varias generaciones que viven en la misma residencia. Esta configuración asociada a situaciones de pobreza, lleva mucha veces a inversión de los roles familiares, siendo los ancianos los jefes de hogar y proveedores de la familia al contar con una fuente de ingresos fijos, a través de la jubilación o pensión. Esta situación ha provocado un aumento del endeudamiento de la tercera edad y es comprensible que para ese grupo la representación social del endeudamiento se relacione con asuntos asociados a salud (enfermedades), sentimientos negativos como culpa, depresión, angustia y vergüenza.

Ya en función de la renta, para el grupo de menores ingresos, el endeudamiento tiene una clara connotación financiera (cuentas, pagos, gastos, etc), la representación es construida desde una perspectiva asociada al dinero, a los recursos y a las limitaciones o restricciones que estos imponen.Esta representación por grupo de ingresos es coincidente con los resultados del análisis estructural. La categoría "Cuenta, Pagos, Gastos" es la que se presenta en destaque en el núcleo central de la representación general. Recordando que las característi- 
cas relacionadas con los elementos del núcleo central, son los aspectos más estables y consensuales de la representación, mientras que, los elementos periféricos son mais cambiantes , flexibles y pueden tener flexibilidad y un carácter individualizado o de gruposDe forma diferente los grupos de mayores ingresos tienen una idea más clara de que el endeudamiento puede ser provocados por exceso de consumo o por problemas de descontrol en los gastos. Para las Clases AB el endeudamiento está lejos de ser representado por la categoría de Cuentas y Gastos, o de Limitación financiera. Sin embargo, para la clase E, la representación del endeudamiento está constituido, además de cuentas y gastos como para las clases D y C, también por situaciones externas la individuoque huyen al control individual., problemas coyunturales que afectan su situación de endeudamiento, desempleo, por ejemplo.

Como fue mencionado antes, el endeudamiento familiar actúe como propulsor de la economía en épocas de prosperidad.En el caso de Brasil, la expansión del crédito se dio de forma excepcionalmente rápida en la última década. Los grupos de menores ingresos vivieron un periodo de auge antes no conocido y disfrutaron de un consumo al cual no estaban acostumbrados.En un panorama de pleno empleo y mercado inmobiliario pujante,el crédito fácilllegaba a las familias deseosas de gastar y adquirir. Sin embargo, ese patrón de crecimiento económico no se sostuvo en el tiempo y la crisis tomó cuenta de la economía a partir de mediados de 2014, los precios comenzaron a subir, se endurecieron las condiciones crediticias, el ingreso disminuyó y el desempleo alcanzó niveles records. Juntando el hábito de comprar en cuotas con la crisis económica y la caída de los ingresos se obtiene como resultado un panoramapropicio para la morosidad. El déficit económico, asociado a la necesidad de tener bienes y servicios que superen el ingreso disponible, evidencia economías vulnerables y riesgosas, incluso a punto de caer en empobrecimiento; si la situación persiste y se torna incontrolable.

El proceso de adaptación a este nuevo horizonte de consumo y gastos no es inmediato. Los segmentos de menores ingresos son más impactados. Además de no contar con ahorros, para eventualidades las personas de menores recursos, en general son trabajadores menos calificados y sufren más con una recesión. Trabajan mayoritariamente en el sector de comercio y servicios, un sector muy impactado por la crisis, así como la construcción y manufactura, y con elevado desempleo. Esto los lleva más fácilmente a ocupaciones informales. De la misma forma, acaban refinanciando los créditos también accediendo al crédito informal (prestamistas, casas de préstamos, retail, etc.) haciendo con que muchas veces el endeudamiento alcance niveles muy elevados del ingreso de estas personas.Por lo tanto, el endeudamiento, visa un contexto de limitación económica y material, asociado a cuentas, gasto y pago, representando una condición antagónica que involucra la imposibilidad naturalizada de combate a factores extrínsecos sobrepujantes y un inevitable constreñimiento por estar permanentemente cerca del peligro no poder honrar las deudas..

Las políticas públicas orientadas al combate del endeudamiento excesivo y sus consecuencias, deben tener como centro de discusión y foco en medidas relacionadas no sólo con la educación financiera de esos grupos menos favorecidos que son llevados a consumir y se endeudar más alla de sus límites sino también deben abordar políticas de salud mental que traten los problemas decurrentes del endeudamiente. De hecho hasta ahora, los debates sobre el tema se han restringido siendo limitados a la dimensión meramente mercantil del fenómeno, descuidando su complejidad y las graves consecuencias que pueden generar sobre los individuos.

A pesar de las limitaciones evidenciadas en este trabajo, comenzando por la naturaleza no probabilística que impiden la generalización de los resultados aquí obtenidos, esta investigación permitió mostrarque el fenómeno del endeudamiento debe ser comprendido en su totalidad como un problema social, de forma tal que permita su problematización por las diferentes áreas del conocimiento. El marketing,por ejemplo, que cumple un papel importante contribuyendo para que la sobre producción de bienes pueda ser vendida, incitando muchas veces al continuo a endeudamiento, debería estudiar de forma más sistemática y consciente las relaciones consumo-endeudamiento, de modo a equilibrar los beneficios de la organización con la satisfacción de las necesidades de los usuarios, sin dejar de lado los intereses públicos y el bienestar social. 


\section{Bibliografía}

Abric, J. C. (2000). A abordagem estrutural das representações sociais. Em A.S.P Moreira y D. C. Oliveira (Orgs.) Estudos interdisciplinares de Representação Social(pp. 27-38). Goiânia, Brasil: AB. doi: 10.1057/ 9781137510778

Awanis, S. y Cui, C.(2014). Consumer susceptibility to credit card misuse and indebtedness. Asia Pacific Journal of Marketing and Logistics, 26 (3), 408-429. doi: 10.1108/APJML-09-2013-0110.

Barkin, D. (2012) Haciaun Nuevo Paradigma Social. Polis [online]. 11(33), 41-58 .doi: 10.4067/S071865682012000300003.

Beal, D. J.yDelpachitra, S. B. (2003).Financial Literacy Among Australian University Students. Economic Papers: A journal of applied economics and policy, (22), 65-78. doi: 10.1111/j.1759-3441.2003.

Brown, S., Taylor, K.y Price, W. S. (2005). Debt and distress: evaluating the psychological cost of credit.Journal of Economic Psychology, 26(5), 642-663.doi: 10.1016/j.joep.2005.01.002.

Bruski, B. y Magalhães, R. S. (2006). Assessing Indebtedness: Results from Pilot Survey among Steelworkers in Sao Paulo. Geneva, Switzerland: International Labour Organization.doi:10.1080/00987913.1978.10763048

Cooper C, Bebbington P.E, Meltzer H, Bhugra D, Brugha T, Jenkins R, Farrell M y King M. (2008).Depression and common mental disorders in lone parents: results of the 2000 national psychiatric morbidity survey. Psychological Medicine, 38, 335-342. doi: 10.1017/S0033291707001493.

Costa, A.(2015). Las ciencias sociales en el laberinto de la economía. Polis [online], 14 (41), 21-42. doi: 10.4067/ S0718-65682015000200002.

Davies, E.y Lea, S. E. G. (1995). The Student attitudes to student debt. Journal of Economic Psychology, 16, 663670. doi:10.1016/0167-4870(96)80014-6.

Denegri, M. (2007). Introducción a la Psicología Económica. Bogotá, Colombia:PSICOM Editores. Recuperado em www.eumed.net/libros/2010b/681/.

Disney, R.yGathergood, J. (2011). Financial Literacy and Indebtedness: New Evidence for UK Consumers. EconPapers, 63 (4), 360-381 Recuperado de https://www.nottingham.ac.uk/cfcm/documents/papers/1105.pdf.

Drentea, P.y Lavrakas, P. J. (2000). Over the limit: the association among health, race, and debt. Social Science and Medicine, 50, 517-529. doi: 10.1016/S0277-9536(99)00298-1

Dwyer, R. E., Mccloud, L. y Hodson, R. (2011).Youth debt, mastery, and self-esteem: Class-stratified effects of indebtedness on self-concept. Social Science Research, 40(3), 727-741.

Guttmann, R., y Plihon, D. (2010). O endividamento do consumidor no cerne do capitalismo conduzido pelas finanças. Economia e Sociedade, 17, 575-610. https://doi.org/10.1590/s0104-06182008000400004

Harrison, N., Agnew, S., y Serido, J. (2015). Attitudes to debt among indebted undergraduates: A cross-national exploratory factor analysis. JournalofEconomicPsychology, , 62-73. doi: 10.1016/j.joep.2014.11.005.

IPEA (2019) - Instituto de Pesquisa Econômica e Aplicada. Carta de Conjuntura, (43). http://www.ipea.gov.br/ portal/index.php?option=com_contentyview=articleyid=34894yItemid=3 
Jessop, D.,Jessop, DC. y Solomon, L (2005). The impact of financial circumstances on student health. British Journal of Health Psychology, 10, 421-439. doi: 10.1348/135910705X25480.

Joo, S. y Grable, J. E. (2004).An Exploratory Framework of the Determinants of Financial Satisfaction. Journal of Family and Economic Issues, 25(1), 25-50.doi: 10.1023/B:JEEI.0000016722.37994.9f.

Kidwell, B.y Turrisi, R. (2004). An examination of college student money management tendencies. Journal of Economic Psychology, 25, 601-616. doi: 10.1016/S0167-4870(03)00073-4.

Lea, S., Webley, P.y Levine, M. (1993). The economic psychology of consumer debt. Journal of Economic Psychology, 14, 85-119. doi: 10.1016/0167-4870(95)00013-4.

Lea, S., Webley, P.y Walker, C. W. (1995). Psychological factors in consumer debt: money management, socialization, and credit use. Journal of Economic Psychology, 16, 681-701. doi: 10.1016/0167-4870(93)90041-I.

Lipovetsky, G. (2007). La felicidadparadójica. Ensayo sobre la sociedade de hiperconsumo. Barcelona, España: Anagrama.

Livingstone, S.y Lunt, P. K. (1992). Predicting personal debt and debt repayment: Psychological, social and economic determinants. Journal of Economic Psychology, 13, 111-134. .doi: 10.1016/0167-4870(92)90055-C.

Moscovici, S. (1984). The Phenomenon of Social Representations. In: R.M. Farr y S. Moscovici (eds.). Social Representations. Cambridge: Cambridge University Press, 3-69. doi: 10.1016/0167-4870(92)90055-C.

Ottaviani, C.yVandone, D. (2011). Impulsivity and household indebtedness: Evidence from real life. Journal of Economic Psychology, ), 754-761. doi: 10.1016/j.joep.2011.05.002.

PNAD (2015).Pesquisa Nacional de Amostra de Domicilios, Sintesis de Indicadores http://www.ibge.gov.br/home/ estatistica/populacao/trabalhoerendimento/pnda2015/sintese_defaultxls.shtm

Raijas, A., Lehtinen, A.y Leskinen, J. (2010). Journal of Consumer Policy,33(3), 209-223. doi: 10.1590/S141565552005000300011.

Sbicca, A., Floriani, V., y Juk, Y. (2014). Expansão do Crédito no Brasil e a Vulnerabilidade do Consumidor. Revista Economia y Tecnologia, 8(4). doi: 10.5380/ret.v8i4.30215

Stone, B., y Maury, R. V. (2006). Indicatorsofpersonal financial debtusing a multi-disciplinarybehavioralmodel. Journal of Economic Psychology, 27(4), 543-556. doi: 10.1016/j.joep.2005.11.002

Tokunaga, H. (1993). The use and abuse of consumer credit: Application of psychological theory and research. Journal of Economic Psychology, 14(2), 285-316. doi: 10.1016/0167-4870(93)90004-5.

Torres, O. y Garces, A. (2013).Representaciones sociales de migrantes peruanos sobre su proceso de integración en la ciudad de Santiago de Chile. Polis [online], 12(35), 309-334. doi: 10.4067/S0718-65682013000200014.

Vergara, S. C. (2008). Métodos de pesquisa em administração. São Paulo, Brasil: Atlas. doi: 10.1590/S141565552005000300011.

Verges, P. (1992). L'évocation de l’argent: une méthode pour ladéfinitiondunoyau central de lareprésentation. Bulletin de Psychologie, 45 (405), 203-209 